\title{
Isolated middle cerebral artery dissection: a systematic review
}

\author{
Ganesh Asaithambi ${ }^{1}$, Pradeepan Saravanapavan ${ }^{1}$, Vaibhav Rastogi ${ }^{1}$, Sheema Khan ${ }^{1}$, Sharatchandra Bidari ${ }^{2}$, \\ Anna Y Khanna ${ }^{1}$, Latha Ganti ${ }^{3}$, Adnan I Qureshi ${ }^{4}$ and Vishnumurthy Shushrutha Hedna ${ }^{* *}$
}

\begin{abstract}
Acute stroke can be missed in the emergency department, particularly in younger patients and in those with more vague symptoms such as headache or dizziness. Cervicocephalic dissections are one group of etiologies for acute stroke in the young. While cervicocephalic dissections are not uncommon in clinical practice, isolated middle cerebral artery dissection (MCAD) has been rarely reported as a cause for stroke. We sought to review the clinical implications and pathophysiology of an isolated MCAD. We searched the medical literature for isolated MCAD in clinical stroke patients using MEDLINE, HighWire, and Google Scholar databases from 1966 to 2013 using the keywords 'middle cerebral artery dissection,' 'intracerebral artery dissection,' and 'middle cerebral artery dissection stroke.' We reviewed cases to learn various characteristics of isolated MCAD. A total of 61 cases $(62.3 \%$ male, mean age $44.16 \pm 19.17$ years) were reviewed from 54 publications. Most cases were reported from Asian countries (78.7\%). Ischemic strokes were more common than hemorrhagic strokes (68.9\%). Digital subtraction angiography was the most common imaging modality used to diagnose isolated MCAD (75.4\%). Surgery was the preferred form of therapeutic intervention (39.3\%). Males $(n=27 / 48, p=0.0008)$ and those who presented with only ischemic syndromes $(n=22 / 48, p=0.0009)$ had significantly higher rates of favorable outcome. Isolated MCAD is a rare disease that can contribute to the stroke burden of young patients. Further studies are needed to better characterize optimal treatment strategies and define outcomes for this rare condition.
\end{abstract}

Keywords: Dissection; Intracranial; Middle cerebral artery; Stroke

\section{Review}

\section{Introduction}

Acute neurological deficits are common emergency department presentations with stroke accounting for up to $3.2 \%$ of emergency department visits [1]. Isolated middle cerebral artery (MCA) dissection (MCAD) is a rarely reported cause of stroke [2,3]. Although the first case was reported in 1915, isolated MCAD remains poorly understood in comparison to dissections of the intracranial internal carotid artery (ICA) with extension into the MCA. Whether an MCAD occurred with or without ICA dissection, cerebral infarction was the main consequence reported. Given the dynamic process of dissection, it is hypothesized that an initial hemodynamic compromise results from stenosis or occlusion from a lumen wall

\footnotetext{
* Correspondence: v.hedna@neurology.ufl.edu

${ }^{1}$ Department of Neurology, University of Florida College of Medicine, HSC Box 100236, Gainesville, FL 32610, USA

Full list of author information is available at the end of the article
}

hematoma with subsequent thrombus formation and distal embolism [4]. A combination of low clinical suspicion and inadequate understanding of the etiology, presentation, imaging findings, and treatment strategies may contribute to the low incidence of isolated MCAD. Therefore, we sought to determine evidence of isolated MCAD through searching the available literature to better understand this unique disease process.

\section{Methods}

A systematic search of MEDLINE, HighWire, and Google Scholar (January 1966 to July 2013) with the keywords 'middle cerebral artery dissection,' 'intracerebral artery dissection', and 'middle cerebral artery dissection stroke' was conducted in subject headings and keywords. Three reviewers (GA, PS, VSH) independently extracted the data from relevant studies, and discrepancies about inclusion were resolved by VSH. Case reports/series describing characteristics of isolated MCAD were included; cases of 
Table 1 Characteristics of isolated middle cerebral artery dissection by study

\begin{tabular}{|c|c|c|c|c|c|c|}
\hline Case report & Age & Gender & Associated conditions & Location & Etiology & Treatment \\
\hline \multicolumn{7}{|l|}{ Ischemia } \\
\hline Piepgras et al. [5] & 56 & $\mathrm{~F}$ & - & M1 & Idiopathic & S \\
\hline Sharif et al. [6] & 17 & M & - & M1 & Trauma & C \\
\hline Adams et al. [7] & 12 & $\mathrm{~F}$ & - & - & Trauma & - \\
\hline Fu et al. [8] & 38 & M & - & M1 & Idiopathic & ET \\
\hline Gotoh et al. [9] & 65 & M & - & M2 & Idiopathic & - \\
\hline Fujimura et al. [10] & 20 & M & Migraine & M1 & Idiopathic & S \\
\hline Kondoh et al. [11] & 66 & M & Sick sinus syndrome & M1 & Idiopathic & $\mathrm{AP}$ \\
\hline Hidaka et al. [12] & 31 & M & - & M2 & Idiopathic & $A C$ \\
\hline Lin et al. [4] & 18 & M & - & M1 & Trauma & $A C$ \\
\hline \multirow[t]{2}{*}{ Lee et al. [13] } & 24 & M & - & M1 & Idiopathic & $A C$ \\
\hline & 50 & $\mathrm{~F}$ & DM & M1 & Idiopathic & AP \\
\hline Prabhakaran et al. [14] & 33 & M & - & M1 & Trauma & $A P+A C$ \\
\hline Hsu et al. [15] & 15 & M & - & M1 & Trauma & $\mathrm{AP}$ \\
\hline Kennedy et al. [16] & 28 & $\mathrm{~F}$ & - & M1 & Idiopathic & AP \\
\hline Verny et al. [17] & 37 & $\mathrm{~F}$ & HTN & M2 & Idiopathic & AP \\
\hline Abe et al. [18] & 27 & M & Tobacco abuse, asthma & M1 & Trauma & S \\
\hline Han et al. [19] & 49 & M & - & M1 & Trauma & $\mathrm{AP}$ \\
\hline Liu et al. [20] & 26 & M & - & M1 & Idiopathic & $\mathrm{AP}$ \\
\hline Suter et al. [21] & 9 & $\mathrm{~F}$ & - & M1 & Idiopathic & - \\
\hline Kato et al. [22] & 46 & M & Hyperlipidemia & M1 & Idiopathic & $A C$ \\
\hline Naggara et al. [23] & 25 & M & - & M1 & Trauma & - \\
\hline Aoki et al. [24] & 57 & M & - & M1 & Idiopathic & $\mathrm{AP}$ \\
\hline Watanabe et al. [25] & 30 & M & - & - & Idiopathic & AP \\
\hline Lee et al. [26] & 56 & $\mathrm{~F}$ & Hyperlipidemia & M1 & Trauma & $\mathrm{IVT}+\mathrm{ET}$ \\
\hline Torihashi et al. [27] & 62 & M & - & M1 & Idiopathic & S \\
\hline Yagi et al. [28] & 72 & $\mathrm{~F}$ & - & M1 & Idiopathic & IVT \\
\hline \multirow[t]{2}{*}{ Chen et al. [29] } & 47 & M & HTN & M1 & Idiopathic & AP \\
\hline & & & Tobacco abuse & & & \\
\hline Doijiri et al. [30] & 45 & M & - & M2 & Idiopathic & IVT \\
\hline \multirow[t]{3}{*}{ Kwak et al. [31] } & 42 & M & DM & M1 & Idiopathic & $A P+A C$ \\
\hline & 46 & $\mathrm{~F}$ & HTN & M1 & Idiopathic & $A P+A C$ \\
\hline & 60 & M & HTN & M1 & Idiopathic & C \\
\hline Jung et al. [32] & 29 & M & - & M1 & Idiopathic & - \\
\hline lida et al. [33] & 53 & M & - & M1 & Idiopathic & $A C$ \\
\hline \multicolumn{7}{|l|}{ Ischemia + hemorrhage } \\
\hline Kawaguchi et al. [34] & 48 & M & - & M2 & Idiopathic & S \\
\hline Hashimoto et al. [35] & 56 & $\mathrm{~F}$ & - & M1 & Idiopathic & S \\
\hline Mizutani et al. [36] & 67 & $\mathrm{~F}$ & - & M1 & Idiopathic & - \\
\hline Abiko et al. [37] & 33 & $\mathrm{~F}$ & - & M1 & Idiopathic & C \\
\hline Niikawa et al. [38] & 46 & $\mathrm{~F}$ & - & M1 & Idiopathic & S \\
\hline \multirow[t]{2}{*}{ Esposito et al. [39] } & 69 & M & HTN & M3 & Idiopathic & S \\
\hline & & & DM & & & \\
\hline Yakushiji et al. [40] & 40 & M & HTN & M1 & Idiopathic & C \\
\hline
\end{tabular}


Table 1 Characteristics of isolated middle cerebral artery dissection by study (Continued)

\begin{tabular}{|c|c|c|c|c|c|c|}
\hline \multicolumn{7}{|l|}{ Hemorrhage } \\
\hline Sasaki et al. [41] & 41 & $\mathrm{~F}$ & - & M2 & Idiopathic & S \\
\hline Chang et al. [42] & 73 & M & HTN & M2 & Idiopathic & C \\
\hline Mizutani et al. [36] & 41 & $\mathrm{~F}$ & - & M1 & Idiopathic & S \\
\hline Abiko et al. [37] & 59 & $\mathrm{~F}$ & - & M1 & Idiopathic & S \\
\hline Bosch et al. [43] & 68 & M & HTN, previous ICH, gout, tobacco abuse & M1 & Idiopathic & - \\
\hline Nimura et al. [44] & 61 & $\mathrm{~F}$ & - & M1 & Idiopathic & S \\
\hline Nakashima et al. [45] & 63 & $\mathrm{~F}$ & HTN & M2 & Idiopathic & S \\
\hline Ono et al. [46] & 68 & $\mathrm{~F}$ & - & M1 & Idiopathic & - \\
\hline Nakashima et al. [47] & 29 & M & - & M2 & Idiopathic & S \\
\hline Isono et al. [48] & 30 & M & - & M1 & Idiopathic & S \\
\hline Sakamoto et al. [49] & 65 & $\mathrm{~F}$ & - & M3 & Idiopathic & S \\
\hline Ning et al. [50] & 50 & M & - & M1 & Idiopathic & S \\
\hline Shioya et al. [51] & 64 & M & - & M2 & Idiopathic & S \\
\hline \multirow[t]{3}{*}{ Peron et al. [52] } & 1.66 & - & - & M1 & Idiopathic & S \\
\hline & 8 & M & - & M1 & Idiopathic & S \\
\hline & 20 & M & - & M1 & Idiopathic & S \\
\hline Saito et al. [53] & 59 & $\mathrm{~F}$ & - & M1 & Idiopathic & S \\
\hline Chuang et al. [54] & 79 & M & HTN & M2 & Idiopathic & S \\
\hline Oyama et al. [55] & 70 & $\mathrm{~F}$ & - & M2 & Idiopathic & S \\
\hline \multicolumn{7}{|l|}{ Transient ischemic attack } \\
\hline Iwamuro et al. [56] & 57 & M & - & M1 & Idiopathic & AP \\
\hline Horie et al. [57] & 37 & M & - & M2 & Idiopathic & - \\
\hline
\end{tabular}

AC, anticoagulation; AP, antiplatelet; $\mathrm{C}$, conservative (conservative treatment indicates medical treatment but unclear if anticoagulant/antiplatelet therapy was included); DM, diabetes mellitus; ET, endovascular treatment; HTN, hypertension; ICH, intracerebral hemorrhage; IVT, intravenous thrombolysis; S, surgery.

MCAD associated with dissections of other vessels were excluded. Articles were assessed for relevancy, and data were compiled for demographics, etiology, symptoms, diagnostic testing, treatment, and outcomes.

Outcomes were dichotomized into favorable and unfavorable, and each case was distributed in either group based on the description provided in the reports. We defined unfavorable outcome as death, modified Rankin Scale (mRS) scores $\geq 2$, or those reported with outcomes as 'moderate', 'poor', or 'severe morbidity.' Fisher's exact tests were then used to determine statistical significance of outcomes based on the clinical characteristics collected. Statistical significance was defined as $p<0.05$. Calculations were performed with SAS software (version 9.4, SAS Institute Inc., Cary, NC, USA).

\section{Results}

Literature review yielded 61 cases $(62.3 \%$ male, median age 46 [interquartile range 29 to 60] years) from 54 published case reports/series of isolated MCAD (Tables 1 and 2). Cases were described from Asian (78.7\%), European (13.1\%), and North American (8.2\%) countries. No reports from South America, Africa, or
Australia fulfilled criteria to be included in our study. Approximately $85.2 \%$ of cases were of spontaneous/ idiopathic etiology with the remainder occurring from traumatic injury. Common stroke risk factors, including hypertension, diabetes mellitus, dyslipidemia, tobacco abuse, and arrhythmia, were reported in $31.1 \%$ of cases. Histories of remote hypertensive intracerebral hemorrhage $(\mathrm{ICH})$ and migraines were also reported.

\section{Presenting symptoms and signs}

Presenting symptoms included headache (44.3\%), seizure (6.6\%), nausea/vomiting (4.9\%), and tinnitus (1.6\%). Depending on laterality, neurologic deficits upon presentation were associated with those commonly found in MCA lesions: weakness (52.5\%), changes in speech (34.3\%), alterations in level of consciousness (27.9\%), numbness (6.6\%), or visual field deficits (1.6\%). Patients presenting without any observed neurological deficits were also common (19.7\%).

\section{Types of strokes}

A majority of the cohort studied presented with ischemic stroke syndromes (68.9\%). Approximately $54.1 \%$ of 
Table 2 Demographic and clinical characteristics of isolated middle cerebral artery dissection

\begin{tabular}{ll}
\hline & Value \\
\hline Age (years) & \\
Median [IQR] & $46[29-60]$ \\
$<45$ & $28(45.9 \%)$ \\
45 to 59 & $17(27.9 \%)$ \\
$>60$ & $16(26.2 \%)$ \\
Gender $(n=60)$ & \\
$38(62.3 \%)$ male & \\
Location $(n=60)$ & \\
M1 & \\
M2 & $45(75 \%)$ \\
M3 & $13(21.7 \%)$ \\
Syndrome $(n=61)$ & $2(3.33 \%)$ \\
Ischemia & \\
Hemorrhage & $33(54.1 \%)$ \\
Ischemia + hemorrhage & $19(31.1 \%)$ \\
Transient ischemic attack & $7(11.5 \%)$ \\
Treatment $(n=56)$ & $2(3.3 \%)$ \\
Surgery & \\
AP & \\
AC & $3(5.4 \%)$ \\
AP + AC & $1(1.7 \%)$ \\
ET & $9(16.1 \%)$ \\
\hline
\end{tabular}

Reported based on available information from publications reviewed. AC, anticoagulation; AP, antiplatelet; ET, endovascular treatment; IVT, intravenous thrombolysis.

patients developed ischemic strokes only, 11.5\% developed concurrent ischemic and hemorrhagic strokes, and 3.3\% developed transient ischemic symptoms. The remaining $31.1 \%$ of reported patients developed either ICH or subarachnoid hemorrhage (SAH). All traumatic MCADs resulted in ischemic syndromes only.

Approximately $37.7 \%$ of patients had aneurysms associated with MCADs. More than half of these patients developed hemorrhagic strokes (13 hemorrhage only, 4 hemorrhage and ischemia). Five patients were found to have ischemic lesions, and one patient developed transient ischemic symptoms.

\section{Diagnostic modalities}

The most commonly used imaging modality for diagnosis was digital subtraction angiography (DSA, 75.4\%) followed by computed tomography/angiography (CT/CTA, 72.1\%), magnetic resonance imaging/angiography (MRI/ MRA, 62.3\%), pathologic evaluation/autopsy (9.8\%), and transcranial Doppler (TCD, 1.6\%). M1 dissections were reported in $75 \%$ of cases, and even more distal dissections (M2 or M3 segments) had higher rates of concurrent aneurysms (10/15 cases).

\section{Treatment approaches}

Surgery (craniotomy with trapping, wrapping, clipping, extracranial-intracranial bypass, or resection) was the preferred form of therapeutic intervention (39.3\%). Intravenous (IV) thrombolytic and endovascular therapies were utilized in only a small minority of cases among those with ischemic syndromes only. Among ischemic strokes only $(n=33)$, long-term antiplatelet therapy $(30.3 \%)$ was preferred over anticoagulation (15.2\%); however, in 9.1\% of cases, antiplatelet therapy and anticoagulation therapy were combined. No preventative strategy was described in $8.2 \%$ of cases, and in another $14.8 \%$ of cases, 'conservative strategies' were described but did not distinguish between antithrombotic use or not. Among patients with SAH/ $\mathrm{ICH}$, six patients did not undergo surgical treatment (three due to death, and three were conservatively managed). Only four patients who presented with isolated ischemic strokes underwent surgery.

\section{Outcomes}

Many cases reviewed for our study used subjective terms to describe patients' outcomes. These terms included 'good,' 'stable, 'mild,' 'able to ambulate,' 'improved', 'independent,' 'stable,' 'no change,' 'moderate,' 'poor,' and 'severe morbidity.' Very few cases (8.2\%) utilized objective measures including the National Institutes of Health Stroke Scale (NIHSS) or mRS to define outcomes. Approximately $18 \%$ of cases did not report outcomes. Of the 48 cases reporting outcomes, 15 patients (mean age $44.64 \pm 22.43$ years) had unfavorable outcomes (Table 3 ). Mortality occurred in 6 of the 15 patients with unfavorable outcomes (mean age $48.5 \pm 26$ years). Males $(n=27 / 48, p=0.0008)$ and those who presented with only ischemic syndromes $(n=22 / 48, p=0.0009)$ had significantly higher rates of favorable outcome. The location of the dissection did not appear to affect the outcome $(p=0.7898)$. Patients who were treated with antiplatelet or anticoagulant therapy had significantly higher rates of favorable outcome $(p=0.0017)$. By grouping age of patients by tertiles $(<45$ years, 45 to 59 years, $>60$ years), no significant differences in outcomes based on age were found (0.3894).

\section{Discussion}

Based on our review, isolated MCAD affects a younger cohort of patients as compared to those who suffer from strokes due to traditional etiologies. Headache appears to be the commonest complaint of the predominantly spontaneous condition. While most patients do not present with focal neurologic abnormalities, those who do present 
Table 3 Outcomes based on clinical characteristics reported

\begin{tabular}{|c|c|c|c|}
\hline \multicolumn{2}{|l|}{ Clinical characteristic } & \multirow{2}{*}{$\begin{array}{l}\text { Favorable outcome } \\
14(29.2 \%)\end{array}$} & \multirow{2}{*}{$\begin{array}{l}\text { Unfavorable outcome } \\
6(12.5 \%)\end{array}$} \\
\hline Age (years, $n=48)$ & $<45$ & & \\
\hline & 45 to 59 & $12(25 \%)$ & $3(6.3 \%)$ \\
\hline & $>60$ & $7(14.5 \%)$ & $6(12.5 \%)$ \\
\hline \multirow[t]{2}{*}{ Gender $(n=47)$} & Female & $6(12.8 \%)$ & $10(21.3 \%)$ \\
\hline & Male & $27(57.4 \%)$ & $4(8.5 \%)$ \\
\hline \multirow[t]{3}{*}{ Location $(n=47)$} & M1 & $25(53.2 \%)$ & $12(25.5 \%)$ \\
\hline & M2 & 7 (14.9\%) & $2(4.3 \%)$ \\
\hline & M3 & $1(2.1 \%)$ & 0 \\
\hline \multirow[t]{4}{*}{ Condition $(n=48)$} & None & $1(2.1 \%)$ & 0 \\
\hline & Ischemic & $22(45.8 \%)$ & $2(4.2 \%)$ \\
\hline & Hemorrhage & $8(16.7 \%)$ & $8(16.7 \%)$ \\
\hline & Ischemia + hemorrhage & $2(4.1 \%)$ & $5(10.4 \%)$ \\
\hline \multirow[t]{6}{*}{ Treatment $(n=48)$} & Antiplatelet & $10(20.8 \%)$ & 0 \\
\hline & Anticoagulation & $3(6.3 \%)$ & 0 \\
\hline & Antiplatelet + anticoagulation & $3(6.3 \%)$ & 0 \\
\hline & Surgery & $13(27.1 \%)$ & $8(16.7 \%)$ \\
\hline & Intravenous thrombolysis & $2(4.1 \%)$ & 0 \\
\hline & Conservative & $2(4.1 \%)$ & $7(14.6 \%)$ \\
\hline
\end{tabular}

with such have common deficits based on location of the MCA territory involved.

Cervicocephalic dissections have been ascribed as a complication of blunt or penetrating trauma; however, spontaneous dissections may be as, or even more, common [3]. The M1 segment of the MCA appears to be most commonly involved in MCAD due to its proximity to the posterior margin of the sphenoid wing; with friction between the M1 segment and this bony anatomic landmark, injury may occur $[4,12,13,15,19,27]$.

There are many associated conditions that may predispose MCAD (or dissections of other cerebral arteries). These include migraine, fibromuscular dysplasia, cystic medial necrosis, intimal fibroelastic irregularities, homocystinuria, periarteritis nodosa, syphilitic arteriopathy, moyamoya disease, atherosclerosis, Guillain-Barre syndrome, Marfan's syndrome, and Ehlers-Danlos syndrome $[2-6,13,18,35,58,59]$. Further, protein expression and activation have been shown to cause occlusion, arterial wall fragility, and rupture of the aneurysm [53].

Dissections, particularly when associated with aneurysms, of the anterior circulation typically manifest as ischemic syndromes, but similar dissections of the posterior circulation usually manifest as SAH $[31,36,41]$. This postulation was based on previously described classifications of intracranial dissecting aneurysms. A type 1 dissecting aneurysm occurs between the internal elastic lamina and the media, causing ischemia from occlusion or stenosis. On the other hand, a type 2 dissecting aneurysm results in SAH due to dissection between the media and the adventitia. Type 2 dissecting aneurysms are commonly found in the posterior circulation, which is why this system has a propensity for SAH $[38,41,49]$. Our review suggested otherwise in that more than half of the patients with aneurysms associated with MCAD developed ICH and/or SAH. When not associated with an aneurysm, however, the rate of ischemic syndromes associated with MCAD was higher.

Both invasive and noninvasive methods have been utilized to detect MCAD. These modalities include CT/CTA, MRI/MRA, DSA, TCD, and pathologic evaluation. While it was previously reported that intracranial dissections are more commonly diagnosed post-mortem, our review of isolated MCAD cases revealed only one report confirming MCAD at the time of autopsy only $[2,7,15]$. DSA is the gold standard for identifying cervicocephalic arterial dissections $[13,20,29]$. However, the use of DSA may not always demonstrate an intimal flap, false lumen, or pseudoaneurysms, which are common entities within a dissection; instead, it commonly can show segmental stenosis of the involved vessel segment $[4,19,20]$. In the setting of a rare condition, intracranial segmental stenoses could lead to an incorrect diagnosis.

Noninvasive imaging may be useful, if not superior based on the modality used, as adjunctive diagnostic testing (Figures 1 and 2). High-resolution MRI (HRMRI) was described as an effective noninvasive means to 


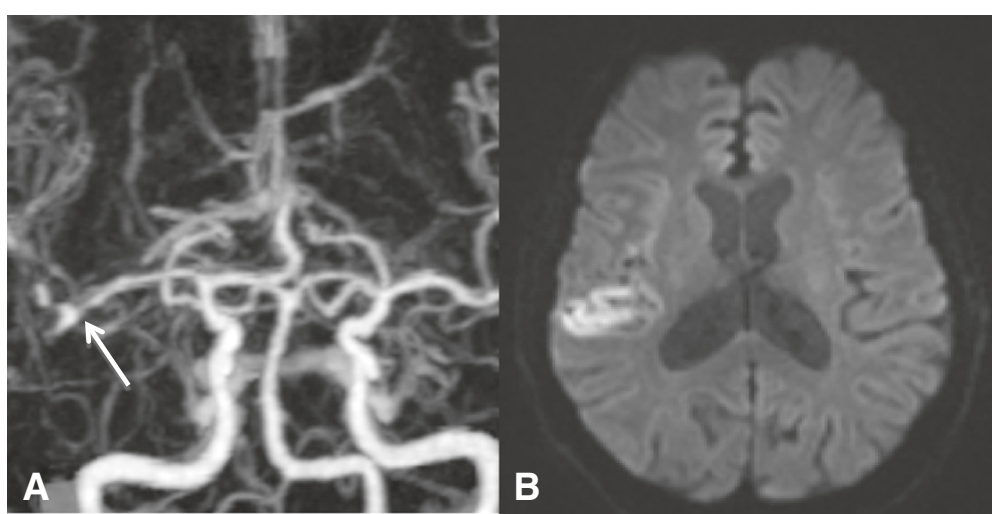

Figure 1 Noninvasive imaging. (A) Three-dimensional 360-slice CTA of the head of a 63-year-old woman presenting with headaches after a motor vehicle collision demonstrating a right $\mathrm{M} 1$ dissection with pseudoaneurysm immediately before the bifurcation (arrow); there is normal caliber of the contralateral MCA. (B) MRI brain shows diffusion restriction within the right perisylvian region consistent with acute ischemia. She was discharged on antiplatelet therapy with a modified Rankin Scale score of 0.

diagnose isolated MCAD based on its ability to pay close attention to the structural characteristics of the vessel wall and lumen [23,26]. Kwak et al. later confirmed the utility of HRMRI by successfully using three-dimensional magnetization-prepared rapid acquisition gradient-echo sequences to detect intimal flaps of dissections and concurrent intramural hemorrhages in their case series [31]. Kato et al. described a

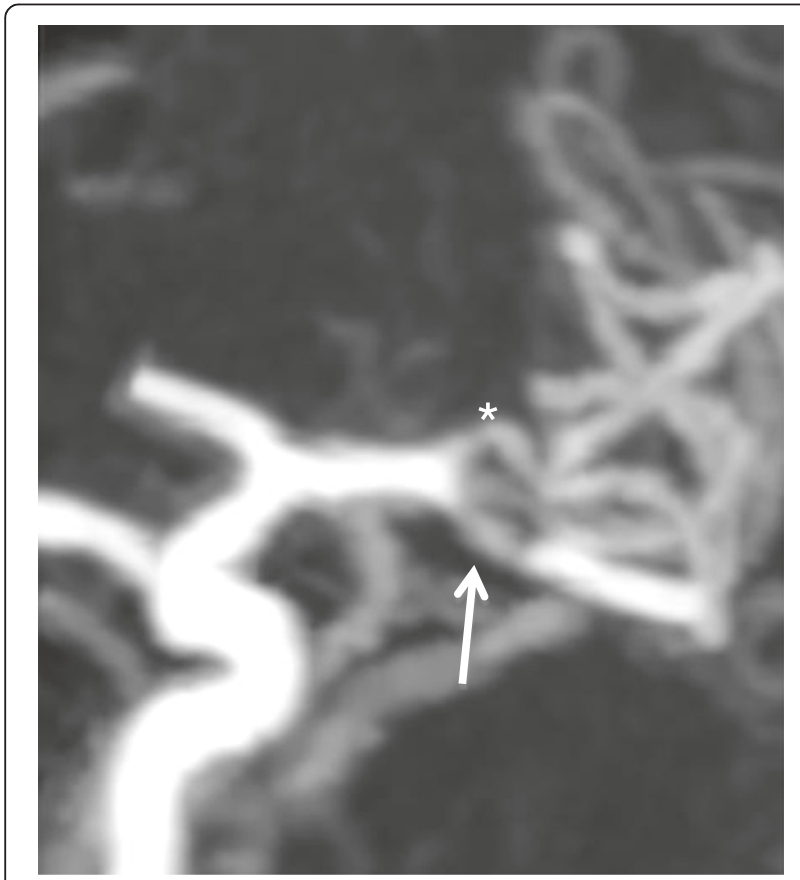

Figure 2 Noninvasive imaging. Three-dimensional 360-slice CTA of the head of a 50-year-old man presenting with abrupt-onset 2-day history of headache and right hemiparesis demonstrating left M1 dissection (arrow) distal to the anterior temporal branch (asterisk). He was discharged on antiplatelet therapy with a modified Rankin Scale score of 0. method of using standard T2-weighted MRI sequencing in the coronal plane parallel to the sylvian vallecula with gray-scale reversal during post-processing that is superior to MRA in detecting MCAD. Yet they note that this anatomically based imaging method is limited to the horizontal segment of the MCA [22]. By an even more crude method, Jung et al. noted a 'shadow sign' on axial T2-weighted MRI sequences, which can suggest intramural hematoma and clinch the diagnosis of dissection; Chen et al. described a similar method as well $[29,32]$. However, invasive and noninvasive neuroradiologic studies can be limiting and may not be sufficient in detecting MCAD. Some reports have described detection of MCAD with associated aneurysmal rupture after patients underwent craniotomy for hematoma evacuation. Once discovered, these lesions were surgically repaired $[45,47,51]$.

The best method of therapeutic intervention for isolated MCAD remains unclear. The treatment strategies included use of antiplatelet agents, anticoagulation, thrombolysis, surgery, endovascular therapy, and no treatment/conservative therapy. While the safety of IV thrombolysis for acute ischemic stroke secondary to extracranial carotid artery dissection has been studied, the safety of thrombolytic use for intracranial dissections remains unknown $[60,61]$. Doijiri et al. reported successful use of IV recombinant tissue plasminogen activator, albeit at a lower than recommended dose of $0.6 \mathrm{mg} / \mathrm{kg}$, without any clear complications [30]. Further studies on the safety and outcomes with the use of IV thrombolysis in acute ischemic stroke from intracranial dissection are needed. There is trepidation with the use of anticoagulation for isolated MCAD-related ischemic syndromes as it may promote progression of intramural hematoma within the dissection [5], whereas others hypothesize that anticoagulation may slow the progression 
of thrombosis that could otherwise lead to a fusiform aneurysm [17]. Endovascular therapies were not abundant in our review, and clinicians may be reluctant to use it beyond the acute setting. While Lee et al. described a successful case of MCAD stenting, stenting may pose a risk to occluding MCA perforators [26,27].

The outcome of strokes secondary to isolated MCAD remains to be established with more objective data. Men and those who have ischemic syndromes appear to have higher rates of favorable outcome based on subjective descriptions. Age did not appear to have a significant effect on outcomes. The benefit of surgery remains unclear, as those who were already at risk for a worse outcome due to hemorrhage were the ones who more commonly underwent surgery. The utility of IV thrombolysis or endovascular therapy requires further evaluation.

While this study is likely the most comprehensive review of isolated MCAD and its clinical implications, it has important limitations. Approximately $23 \%$ of cases reported were written in alternate languages with only abstracts available in English. With review of abstracts only, key characteristics of reported patients are missed. While most reported cases were from Asian countries, to suggest that Asians are more susceptible to isolated MCAD would introduce a selection bias. Formal outcome scales were rarely used, including the NIHSS or mRS scores. Therefore, our definition of unfavorable outcomes was based on subjective descriptions. Without standardized outcome definitions, the best therapeutic interventions remain unknown, as it was based on expert opinion case-by-case. Prospective studies are needed to define outcomes based on therapeutic interventions.

\section{Conclusions}

Isolated MCAD remains an underreported cause of stroke that affects a younger population than commonly seen by traditional etiologies of stroke. While more likely to result in ischemic strokes, hemorrhagic strokes can occur especially when associated with aneurysms. Isolated MCAD is most likely to be idiopathic/spontaneous in etiology and affects a younger population. Noninvasive diagnostic studies are capable of detecting this condition when there is a high index of clinical suspicion. Optimal therapeutic interventions remain unclear, and unfavorable outcomes are higher among those who have hemorrhagic strokes. Further studies are needed to better characterize optimal treatment strategies that give patients the highest chance of favorable outcomes.

\section{Competing interests}

The authors declare that they have no competing interests.

\section{Authors' contributions}

GA prepared the manuscript and collected data for the study. PS collected data for the study. VR and SK participated in manuscript preparation. SB reviewed sample patient case imaging studies and critically appraised the manuscript. AYK, LG, and AIQ critically appraised the manuscript. VSH conceived the study and participated in its design and coordination. All authors read and approved the final manuscript.

\section{Acknowledgements}

The authors would like to thank Hongzhi $\mathrm{Xu}, \mathrm{PhD}, \mathrm{MPH}$, for assistance in statistical analysis.

\section{Disclosures}

The authors have not received any financial support for this work from any organization and do not report any other conflicts of interest. AIQ. has received funding from the National Institutes of Health U01-NS062091-01A2 (medication provided by EKR Therapeutics), the American Heart Association Established Investigator Award 0840053N, and the Minnesota Medical

Foundation, Minneapolis, Minnesota.

\section{Author details}

'Department of Neurology, University of Florida College of Medicine, HSC Box 100236, Gainesville, FL 32610, USA. ²Department of Radiology, University of Florida College of Medicine, Gainesville, FL 32610, USA. ${ }^{3}$ North Florida South Georgia Veterans Affairs Medical Center, 1601 Archer Road, Gainesville, FL 32610, USA. ${ }^{4}$ Zeenat Qureshi Stroke Institute, 519 2nd St N, St Cloud, MN 56303, USA.

Received: 8 September 2014 Accepted: 12 November 2014

Published online: 17 December 2014

\section{References}

1. National Hospital Ambulatory Medical Care Survey: 2010 emergency department summary tables. http://www.cdc.gov/nchs/data/ahcd/ nhamcs_emergency/2010_ed_web_tables.pdf. Accessed 7 September 7 2014.

2. Schievink WI, Mokri B, Piepgras DG: Spontaneous dissections of cervicocephalic arteries in childhood and adolescence. Neurology 1994, 44(9):1607-1612.

3. Biller J, Hingtgen WL, Adams HP, Smoker WR, Godersky JC, Toffol GJ: Cervicocephalic arterial dissections. A ten-year experience. Arch Neurol 1986, 43(12):1234-1238.

4. Lin CH, Jeng JS, Yip PK: Middle cerebral artery dissections: differences between isolated and extended dissections of internal carotid artery. J Neurol Sci 2005, 235(1-2):37-44.

5. Piepgras DG, McGrail KM, Tazelaar HD: Intracranial dissection of the distal middle cerebral artery as an uncommon cause of distal cerebral artery aneurysm. Case report. J Neurosurg 1994, 80(5):909-913.

6. Sharif AA, Remley KB, Clark HB: Middle cerebral artery dissection: a clinicopathologic study. Neurology 1995, 45(10):1929-1931.

7. Adams C, Trevenen C: Middle cerebral artery dissection. Neuropediatrics 1996, 27(6):331-332.

8. Fu Y, Komiyama M, Inoue T, Ohata K, Matsuoka Y, Hakuba A: A case of middle cerebral artery occlusion caused by dissecting aneurysm. No Shinkei Geka 1996, 24(10):955-959.

9. Gotoh T, Hashimoto Y, Yonehara T, Uchino M, Ando M: A case of cerebral infarction due to dissection in a branch of the middle cerebral artery. Rinsho Shinkeigaku 1996, 36(2):312-317.

10. Fujimura M, Seki H, Sugawara T, Sakuma T, Otawara Y, Harata N: Giant thrombosed fusiform aneurysm at the branch of the middle cerebral artery presenting with intramural hemorrhage: a case report. No Shinkei Geka 1997, 25(2):151-155.

11. Kondoh R, Utsugisawa K, Obara D, Mizuno M, Yonezawa H, Terayama Y: Striatocapsular infarction caused by middle cerebral artery dissection. Eur Neurol 2004, 51(2):120-121.

12. Hidaka D, Toyoda K, Fujimoto S, Yasumori K, Okada Y: Ischemic stroke in a young adult due to dissection of a branch of the middle cerebral artery. Intern Med 2005, 44(5):505-506.

13. Lee JS, Bang OY, Lee PH, Kim BM, Yong SW: Two cases of spontaneous middle cerebral arterial dissection causing ischemic stroke. J Neurol Sci 2006, 250(1-2):162-166.

14. Prabhakaran S, Krakauer JW: Multiple reversible episodes of subcortical ischemia following postcoital middle cerebral artery dissection. Arch Neurol 2006, 63(6):891-893. 
15. Hsu KC, Kao HW, Chen SJ: Backward somersault as a cause of childhood stroke: a case report of isolated middle cerebral artery dissection in an adolescent boy. Am J Emerg Med 2008, 26(4):519.e513-515

16. Kennedy G: Spontaneous Anterior Intracranial Artery Dissection: An Important Cause of Stroke in Young People. Adv Clin Neurosci Rehabil 2008, 8:30-31.

17. Verny C, Marc G, Pasco A, Dubas F: Middle cerebral artery dissection gives rise to giant serpentine aneurysm. Cerebrovasc Dis 2008, 25(3):283-285.

18. Abe A, Nishiyama Y, Kamiyama H, Kitahara I, Katsura K, Katayama Y: Symptomatic middle cerebral artery dissection in a young tennis player. J Nippon Med Sch 2009, 76(4):209-211.

19. Han SR, Lee SJ, Yee GT, Choi CY, Sohn MJ, Lee CH: Post-traumatic middle cerebral artery dissection-a case report. J Korean Neurotraumatology Soc 2009, 5(1):22-24

20. Liu YC, Chung CP, Yip PK, Wang V: Spontaneous middle cerebral arterial dissection presented with limb shaking. Acta Neurol Taiwan 2009, 18(1):26-29.

21. Suter B, El-Hakam LM: Child neurology: stroke due to nontraumatic intracranial dissection in a child. Neurology 2009, 72(19):e100.

22. Kato Y, Dembo T, Takeda H, Uchino A, Deguchi I, Furuya D, Tanahashi N: Outer contour of middle cerebral artery revealed by sylvian vallecula-paralle anatomic scanning-magnetic resonance imaging: a method useful for detecting dissection. Arch Neurol 2010, 67(10):1278-1279.

23. Naggara O, Oppenheim C, Louillet F, Touzé E, Mas JL, Leclerc X, Meder JF: Traumatic intracranial dissection: mural hematoma on high-resolution MRI. J Neuroradiol 2010, 37(2):136-137.

24. Aoki N, Sakai T, Oikawa A, Takizawa T, Koike M: Dissection of the middle cerebral artery caused by invasion of malignant glioma presenting as acute onset of hemiplegia. Acta Neurochir (Wien) 1999, 141(9):1005-1008.

25. Watanabe M, Inatomi Y, Yonehara T, Fujioka S, Uchino M: Serial magnetic resonance images in patient with the middle cerebral artery dissection. Rinsho Shinkeigaku 2002, 42(7):608-612.

26. Lee HO, Kwak HS, Chung GH, Hwang SB: Diagnostic usefulness of high resolution cross sectional MRI in symptomatic middle cerabral arterial dissection. J Korean Neurosurg Soc 2011, 49(6):370-372

27. Torihashi K, Chin M, Sadamasa N, Yoshida K, Narumi O, Yamagata S: Ischemic stroke due to dissection of the middle cerebral artery treated by superficial temporal artery-middle cerebral artery anastomosis-case report. Neurol Med Chir (Tokyo) 2011, 51(7):503-506.

28. Yagi $\mathrm{R}$, Sugie $\mathrm{A}$, Kobata $\mathrm{H}$ : Middle cerebral artery dissection treated with intravenous tissue plasminogen activator injection: a case report. No Shinkei Geka 2011, 39(3):275-279.

29. Chen ZC, Sun JZ, Shi ZH, Lou M: Capsular warning syndrome caused by spontaneous middle cerebral artery dissection. CNS Neurosci Ther 2012 18(8):702-704

30. Doijiri R, Yokota C, Suzuki R, Toyoda K, Minematsu K: Intravenous recombinant tissue plasminogen activator thrombolysis in acute ischemic stroke due to middle cerebral artery dissection. J Stroke Cerebrovasc Dis 2012, 21(8):915.e917-919.

31. Kwak HS, Hwang SB, Chung GH, Jeong SK: High-resolution magnetic resonance imaging of symptomatic middle cerebral artery dissection. J Stroke Cerebrovasc Dis 2014, 23(3):550-553.

32. Jung $J M$, Lee $Y H$, Park MH, Kwon DY: Shadow sign in a $T_{2}^{*}$ brain image in spontaneous middle cerebral artery dissection. Neurology 2013, 80(4):419.

33. lida $H$, Kusumi M, Sagiuchi $T$, Mitomi $T$ : Cerebral infarction and fluid collection due to an enlarged dissecting aneurysm of the middle cerebral artery-case report. Neurol Med Chir (Tokyo) 2004, 44(10):535-539.

34. Kawaguchi T, Kawano T, Kazekawa K, Honma T, Kaneko Y, Koizumi T, Dousaka Y: Dissecting aneurysm of the middle cerebral artery with subarachnoid hemorrhage and brain infarction: a case report. No Shinkei Geka 1997, 25(11):1033-1037.

35. Hashimoto H, lida J, Shin Y, Hironaka Y, Sakaki T: Subarachnoid hemorrhage from intracranial dissecting aneurysms of the anterior circulation. Two case reports. Neurol Med Chir (Tokyo) 1999, 39(6):442-446.

36. Mizutani T: Subarachnoid hemorrhage associated with angiographic "stenotic" or "occlusive" lesions in the carotid circulation. Surg Neurol 1998, 49(5):495-503. discussion 503-494.

37. Abiko S, Okamura T, Kurokawa Y, Ikeda N, Ideguchi M, Watanabe K: Diagnosis and treatment of nontraumatic dissecting aneurysm in the middle cerebral artery. No Shinkei Geka 1999, 27(8):743-749.
38. Niikawa S, Yamada J, Sumi Y, Yamakawa H: Dissecting aneurysm of the middle cerebral artery manifesting as subarachnoid hemorrhage and hemorrhagic infarctions-case report. Neurol Med Chir (Tokyo) 2002, 42(2):62-66.

39. Esposito G, Albanese A, Sabatino G, Scerrati A, Sturiale C, Pedicelli A, Pilato F, Maira G, Di Lazzaro V: Large middle cerebral artery dissecting aneurysm mimicking hemorrhagic stroke. Clin Neurol Neurosurg 2011 113(10):901-903.

40. Yakushiji Y, Haraguchi Y, Soejima S, Takase Y, Uchino A, Koizumi S, Kuroda Y: A hyperdense artery sign and middle cerebral artery dissection. Intern Med 2006, 45(22):1319-1322.

41. Sasaki O, Koike T, Tanaka R, Ogawa H: Subarachnoid hemorrhage from a dissecting aneurysm of the middle cerebral artery. Case report. J Neurosurg 1991, 74(3):504-507.

42. Chang CC, Noji M, Kuwana N: Dissecting aneurysm of the middle cerebral artery associated with subarachnoid haemorrhage. J Clin Neurosci 1998, 5(3):361-363.

43. Bosch J, Mauleón A, Coscojuela P, Porta I, Grivé E, Alvarez-Sabín J, Vilalta J, Molins M, Codina A: Intraventricular hemorrhage due to the rupture of atherosclerotic dissecting aneurysm of the middle cerebral artery. Rev Neurol 1999, 28(10):973-975.

44. Nimura T, Oku T, Narita N, Higuchi H: Dissecting aneurysm of the middle cerebral artery: case report. No Shinkei Geka 2000, 28(1):61-65.

45. Nakashima S, Shimokawa S, Nakagawa S, Tomokiyo M, Furukawa Y, Anegawa S, Hayashi T: A case of aneurysm of the peripheral middle cerebral artery undetectable on preoperative angiogram. No Shinkei Geka 2001, 29(6):545-549.

46. Ono Y, Kawamura T, Ito J, Kanayama S: Dissecting aneurysm of the middle cerebral artery (M1-2 portion) with subarachnoid hemorrhage: a case report. No Shinkei Geka 2001, 29(4):347-352

47. Nakashima S, Nomura S, Tomokiyo M, Furukawa Y, Shimokawa S, Nakagawa S, Anegawa S, Hayashi T: Dissecting aneurysm of the middle cerebral artery with subarachnoid hemorrhage showing complete occlusion at the M2 portion of the middle cerebral artery on preoperative angiograms: case report. No Shinkei Geka 2002, 30(5):541-545.

48. Isono M, Abe T, Goda M, Ishii K, Kobayashi H: Middle cerebral artery dissecting aneurysm causing intracerebral hemorrhage 4 years after the non-hemorrhagic onset: a case report. Surg Neurol 2002, 57(5):346-349. discussion 349-350.

49. Sakamoto S, Ikawa F, Kawamoto H, Ohbayashi N, Inagawa T: Acute surgery for ruptured dissecting aneurysm of the M3 portion of the middle cerebral artery. Neurol Med Chir (Tokyo) 2003, 43(4):188-191.

50. Ning L, Kato $Y$, Sano H, Nair RB, Yoneda M, Watanabe S, Kanno T: Spontaneous dissecting aneurysm of middle cerebral artery: a case report with review of the literature. Minim Invasive Neurosurg 2003 46(6):357-360.

51. Shioya H, Kikuchi K, Suda Y, Shoji H, Shindo K: Dissecting aneurysm of the middle cerebral artery with subarachnoid hemorrhage undetectable on preoperative neuroradiological findings: case report. No To Shinkei 2004, 56(11):965-970.

52. Peron S, Jimenez-Roldán L, Cicuendez M, Millán JM, Ricoy JR, Lobato RD Alday R, Alén JF, Lagares A: Ruptured dissecting cerebral aneurysms in young people: report of three cases. Acta Neurochir (Wien) 2010, 152(9):1511-1517.

53. Saito A, Fujimura M, Inoue T, Shimizu H, Tominaga T: Lectin-like oxidized low-density lipoprotein receptor 1 and matrix metalloproteinase expression in ruptured and unruptured multiple dissections of distal middle cerebral artery: case report. Acta Neurochir (Wien) 2010, 152(7):1235-1240.

54. Chuang MJ, Lu CH, Cheng MH: Management of middle cerebral artery dissecting aneurysm. Asian J Surg 2012, 35(1):42-48.

55. Oyama H, Kito A, Maki H, Hattori K, Noda T, Wada K: Treatment of a cerebral dissecting aneurysm in anterior circulation: report of 11 subarachnoid hemorrhage cases. Nagoya J Med Sci 2012, 74(3-4):325-338.

56. Iwamuro $Y$, Jito J, Shirahata M, Tokime T, Hosotani K, Tokuriki Y: Transient ischemic attack due to dissection of the middle cerebral artery-case report. Neurol Med Chir (Tokyo) 2001, 41(8):399-401.

57. Horie N, Takahashi N, Furuichi S, Mori K: Giant fusiform aneurysm with dissection in the middle cerebral artery: a case report. No To Shinkei 2002, 54(2):147-151. 
58. Kurino M, Yoshioka S, Ushio Y: Spontaneous dissecting aneurysms of anterior and middle cerebral artery associated with brain infarction: a case report and review of the literature. Surg Neurol 2002, 57(6):428-436. discussion 436-428.

59. Otawara Y, Suzuki M, Abe M, Tomizuka N, Ogawa A: Dissecting aneurysms of the anterior cerebral artery and accessory middle cerebral artery. Case report. Neurosurg Rev 1997, 20(2):145-148.

60. Georgiadis D, Lanczik O, Schwab S, Engelter S, Sztajzel R, Arnold M, Siebler M, Schwarz S, Lyrer P, Baumgartner RW: IV thrombolysis in patients with acute stroke due to spontaneous carotid dissection. Neurology 2005 64(9):1612-1614.

61. Qureshi Al, Chaudhry SA, Hassan AE, Zacharatos H, Rodriguez GJ, Suri MF, Lakshminarayan K, Ezzeddine MA: Thrombolytic treatment of patients with acute ischemic stroke related to underlying arterial dissection in the United States. Arch Neurol 2011, 68(12):1536-1542.

doi:10.1186/s12245-014-0044-1

Cite this article as: Asaithambi et al:: Isolated middle cerebral artery dissection: a systematic review. International Journal of Emergency

Medicine 2014 7:44.

\section{Submit your manuscript to a SpringerOpen ${ }^{\circ}$ journal and benefit from:}

- Convenient online submission

- Rigorous peer review

- Immediate publication on acceptance

- Open access: articles freely available online

- High visibility within the field

- Retaining the copyright to your article 